\begin{tabular}{|c|c|c|c|}
\hline$\Omega$ & (1) & $\equiv$ & (2) \\
\hline W. De Backer', & 'Dept of Pulmonary & W. De Backer: University & wilfried.debacker@ua.ac.be \\
\hline S. Mitchell ${ }^{2}$, & Medicine, University of & Hospital Antwerp, & \\
\hline on behalf of the & $\begin{array}{l}\text { Antwerp, Antwerp, Belgium } \\
{ }^{2} \text { European Respiratory }\end{array}$ & $\begin{array}{l}\text { Department of Pneumology, } \\
\text { Wilriikstr. 10. Antwerp. }\end{array}$ & \\
\hline respiratory Sleep & Society, Lausanne, & 2650, Belgium & \\
\hline HERMES Task Force & 7 & & \\
\hline
\end{tabular}

\title{
Respiratory Sleep HERMES: new considerations in project development
}

Launched in 2009, the European Respiratory Society (ERS) Respiratory Sleep HERMES project aimed to design and implement core educational activities supported by a network of initiatives to standardise training and education in respiratory sleep medicine (fig. 1).

Using the framework established by HERMES, the project task force has begun to move through each development phase successfully publishing a syllabus of what a respiratory sleep specialist should know [1], and supporting these modules through the publication of the ERS Handbook of Respiratory Sleep Medicine [2].

Perhaps the greatest challenge of the HERMES initiative is the application of a standardised methodology to medical specialties that are in essence different. To date, seven HERMES projects have been launched (fig. 2). The training characteristics vary from skillsbased training, services-based training and subspecialty or tertiary-based training. For each project, all healthcare professionals are considered from medical physicians and multidisciplinary teams to non-medical practitioners.

The purpose of this editorial is to revisit how the respiratory sleep HERMES task force intends to take next project steps ensuring that:

1. Consideration is given to all healthcare professionals working in respiratory sleep, including technicians, nurses and respiratory physicians;
2. Applied levels of competence are relevant not only for respiratory physicians working in sleep clinics but also for allied health professionals working in this field;

3. Corresponding sleep projects and educational activities implemented by other European societies are considered in project development.

The task force will need to consider each of these points and how best to achieve a complete educational programme for all healthcare professionals working in respiratory sleep medicine.

\section{Application of the respiratory sleep syllabus and curriculum to allied health professionals}

In September 2011, Dr B. Cooper, Head of Assembly 9 of the ERS, was invited to attend the respiratory sleep HERMES task force meeting in Amsterdam to discuss the application of the respiratory sleep syllabus to allied health professionals. All task force members agreed that the respiratory sleep HERMES project could not only focus on respiratory physicians but also needed to be applied to non-medical practitioners working in sleep clinics. Three representatives from Assembly 9 were selected to complete a survey to:
Statement of Interest

S. Mitchell is an employee of the European Respiratory Society.
The respiratory sleep HERMES task force:

Wilfried de Backer, Stefan Andreas, Marisa Bonsignore, Viliam Donic, Patrick Levy, Walter McNicholas, Mary Morrell, Paolo Palange, Winfried Randerath, Renata Riha, Anita Simonds, $\mathrm{Ha}$ Trang, Johan Verbraecken 


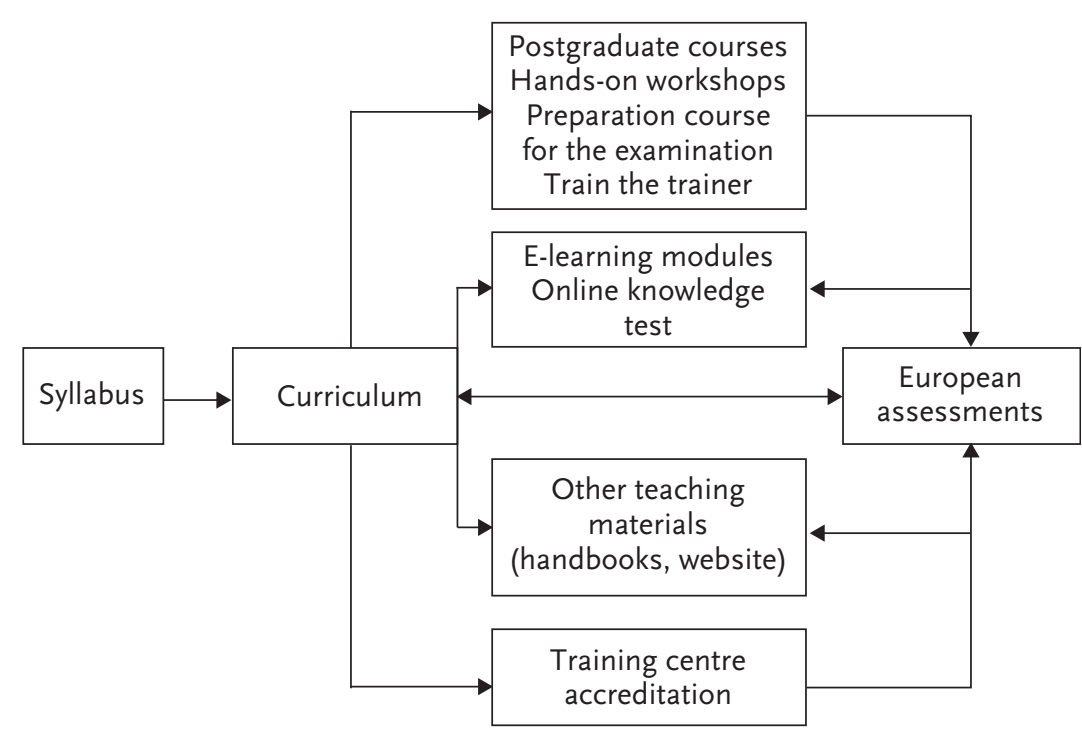

Figure 1

The HERMES structure for developing standardised training and education in specialist areas of respiratory medicine.

i. Identify which items from the respiratory sleep HERMES syllabus were relevant to allied health professionals working in sleep clinics in their countries;

ii. Stipulate any additional items which may be relevant to non-medical practitioners working in respiratory sleep clinics;

iii. Assign a level of competence to each item.

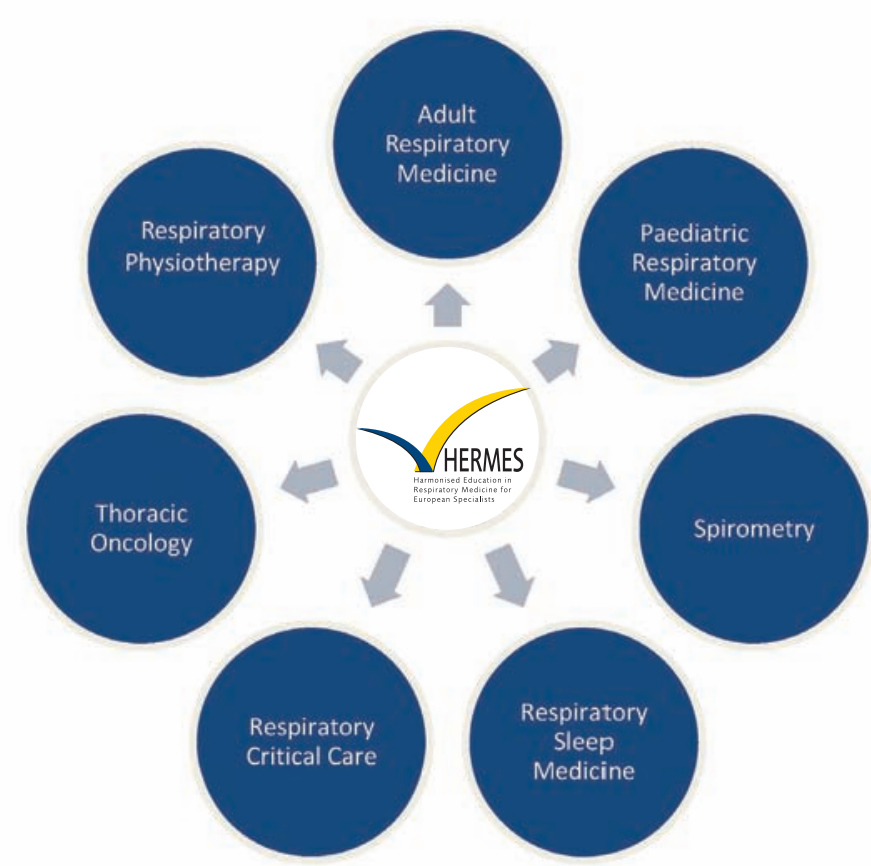

Figure 2

HERMES Project family 2005-2012.
Results of this survey clearly highlight that most of the modules and items are also relevant for non-medical practitioners working in sleep clinics. For the curriculum development, the knowledge, skills, attitudes and behaviours will apply to all health professionals working in sleep clinics.

\section{HERMES Levels of competence}

During the syllabus Delphi rounds in 2011, the task force restructured the levels of competence to apply specifically to professionals working in respiratory sleep. However, there was still some confusion about the applied competence levels and so the rationale to reassess the levels of competence were clear:

i. The gold standard framework Miller's model of clinical competence has been adopted as the framework which will be applied to all future HERMES projects. This model shows a progression towards expertise (fig. 3);

ii. Standardising the HERMES methodology The assignment of a new HERMES director and establishment of a new HERMES board aim to ensure that all HERMES projects follow a similar developmental process, following best practice standards.

Given this rationale, all task force members agreed that moving forward the levels of competence will be rewritten to reflect this model.

Level 1 Foundation competency to be used in daily practice by everybody involved in the field. It is a requisite to function in the multidisciplinary team/setting.

This competency level pertains to "knowing" and "knowing how" and is considered as the first step in the competency ladder.

Level 2 Intermediate competency to be demonstrated and applied with consultation, or under supervision and/or referral.

This competency level pertains to "showing how" to perform a specific skill or competent to refer to another specialty.

Level 3 Specialised competency which has the highest level of complexity and specialisation. This advanced level of specialisation pertains to those who "do" by specialists practicing independently. 
Going forward, the levels of competence will be applied and implemented during the curriculum Delphi process and ensure that these levels are relevant to all those working in the field of respiratory sleep medicine.

\section{Consideration of corresponding sleep projects}

A further consideration of the task force during project development was based on the discussion on whether sleep medicine needs to be established as a sub-specialty within Europe. The implications of these discussions presuppose the need to consider other societies conducting simultaneous projects in sleep medicine. With similar intended project aims, the European Sleep Research Society (ESRS) and ERS have agreed to collaborate in establishing a vision of how sleep medicine can be organised within Europe, and to prescribe a set process to attain this goal.

With seven ongoing HERMES projects in development at different stages, alternative training characteristics and target audiences, there is a need to revisit project phases and the application of the HERMES methodology. This is certainly true for the respiratory sleep HERMES project and has allowed the task force to call into question new and important dimensions including levels of competence, target audience and collaboration with European societies. The assistance of the new medical education advisor to ERS school committee, $\operatorname{Dr}$ J.O. Busari, and the newly appointed HERMES director post has ensured that the intricacies of each project can be
Miller's model of clinical competence

Respiratory Sleep HERMES

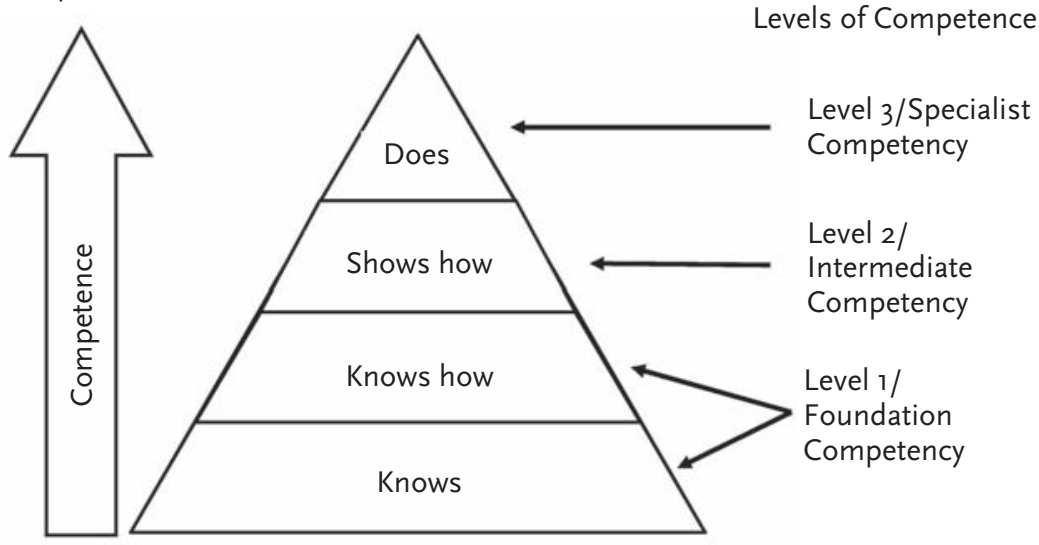

Figure 3

Millers model of clinical competence. Reproduced and modified from [3] with permission from the publisher.

realised while continuing to follow the HERMES framework. The respiratory sleep task force anticipate the next phase of development with the publication of a curriculum in respiratory sleep medicine describing how the knowledge and skills of a syllabus should be taught and learned.

\section{Acknowledgements}

The respiratory sleep HERMES task force would like to acknowledge the support and commitment to this project from J.O. Busari (Heerlen, the Netherlands), Medical Education Advisor to the ERS School committee, B.G. Cooper (Birmingham, UK), Head of Assembly 9 Sept 2009-Sept 2012, and P. Palange (Rome, Italy), HERMES Director within the ERS School Committee.

\section{References}

1. De Backer W, Simonds A, Horn V, et al. Sleep HERMES: A European Core Syllabus in Respiratory Disorders during sleep. Breathe 2011; 8: 61-68.

2. Simonds A, de Backer W, eds. ERS Handbook of Respiratory Sleep Medicine. European Respiratory Society: Sheffield, 2012.
3. Miller GE. The assessment of clinical skills/competence/performance. Acad Med 1990; 65: S63-S67. 